\title{
Speed of light, the vanished points of reference
}

\author{
Harry H. Mark \\ 16 Broadway, Yale-New Haven Hospital, North Haven, CT 06473
}

\author{
Email address: \\ iimd@aol.com
}

\section{To cite this article:}

Harry H. Mark. Speed of Light, the Vanished Points of Reference. Optics. Vol. 3, No. 2, 2014, pp. 12-14. doi: $10.11648 /$ j.optics.20140302.11

\begin{abstract}
At the suggestion of H.A. Lorentz, Michelson's famous experiment of 1881 was repeated in 1887 because of an alleged error pointed out by Potier. By overlooking a minor omission when compounding the newer data, the suggested correction did not materially change the original conclusion, namely, that light was propagated with constant speed (c) irrespective of the motion of its source or observer, contrary to classical Galilean principles. Though universally accepted, careful analysis reveals that, aside from the computational error, old forgotten actual astronomical data militate against this interpretation. Bypassing the limiting constant (c) may therefore open the road to advances in optics.
\end{abstract}

Keywords: Speed of Light, Michelson, Lorentz, Universal Constants

\section{Michelson's Experiment}

As Nobel laureate Max Planck put it: "The Theory of Relativity was led up to by Michelson's experiments on optical interference" [1], and since this theory took center stage in Theoretical Physics in the past century, it was deemed worthwhile to explore the validity of the experiment's interpretations.

In his reports from 1881/1882 [2, 3] Albert A. Michelson (1852 - 1931) set out by defining the given premises: "Assuming then that the ether is at rest the earth is moving through it." The ether was "at rest" in reference to what? Since Galileo and Newton this meant in reference to the fixed stars or sun. "The earth is moving" obviously in reference to the same stationary firmament. " $v=$ the speed of the earth with respect to the ether ["at rest"]." "D = the distance between two points" on his apparatus. " $d=$ the distance through which the earth moves while light travels from one point to the other [on the apparatus]. $d_{1}=$ the distance earth moves while light passes in the opposite direction." All these values were then in reference to a stationary point outside the earth (Figure 1, right)

Now comes the crux of the problem: "Let $\mathrm{V}$ be the velocity of light". No point of reference was given, but as Michelson himself measured many times, it meant the velocity of light emitted in his apparatus, which was stationed with him on earth moving in reference to the stars. In reference to this point its velocity is $\mathrm{V}+\mathrm{v}$. There was no reason whatsoever in 1881, empirical or theoretical, to deviate from classical Galilean and Newtonian principles, and omit compounding the velocity of light by that of the earth, setting it simply at V. The velocity of light was thus $a$ priori already independent of the velocity of its source.

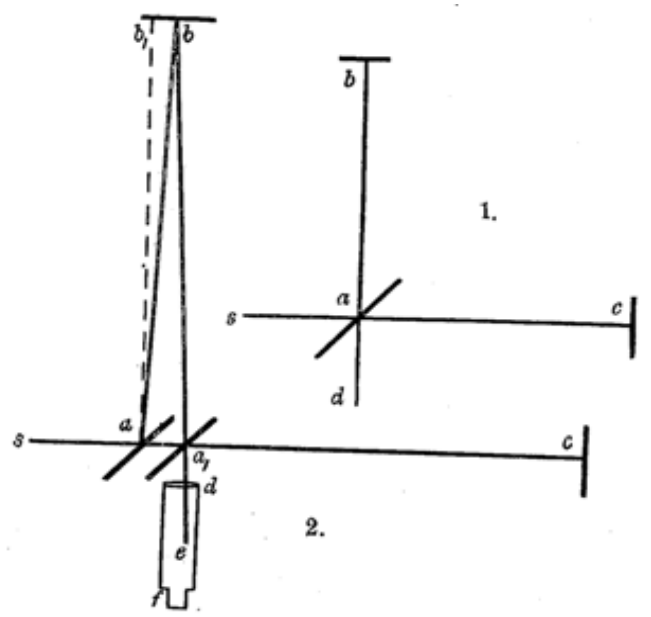

Fig. 1 . The paths of rays in the $1881 / 1882$ reports (1. on right) and in 1887 (2. on left).

He then computed " $\mathrm{T}=\mathrm{D}+\mathrm{d} / \mathrm{V}=\mathrm{d} / \mathrm{v}$ " or : $\mathrm{V}=\mathrm{D}+\mathrm{d} / \mathrm{T}$. The distance that light moved in direction of the motion of the earth increased by $d$ in reference to the firmament, but $\mathrm{V}$ did not. "If however light had traveled in a direction at right angles to the earth's motion it would be entirely unaffected." The distances being in this manner different, but light's velocity not compounded accordingly, everyone 
naturally expected a shift in the interference bands, but, alas, none ensued.

In the winter of 1881/1882 Alfred Potier pointed out that the earth's motion in reference to the firmament did have an effect on light's perpendicular course, and Michelson therefore increased this distance (Figure 1, left). "In consequence the quantity to be measured had in fact but one-half the value supposed." [4] $\mathrm{Had}$ he also correspondingly increased the velocity $\mathrm{V}$ in direction of the earth's motion "the quantity to be measured" would be zero, that is, both lights return at the same time -- and no one would have been surprised.

Figure 2 represents the Galilean circumstances as seen from a stationary reference point outside cabin $\mathrm{ABCD}$ (say $4 \times 4$ meters in size). Two light beams (or balls) are sent simultaneously at right angles from A (say at speeds of $4 \mathrm{~m} / \mathrm{sec}$ ). At standstill the vertical one moves from corner A to $\mathrm{B}$, while the horizontal one from $\mathrm{A}$ to $\mathrm{D}$. They bounce back to point $\mathrm{A}$ after 2 seconds. When the cabin moves uniformly from point A to point a (at speed of $3 \mathrm{~m} / \mathrm{sec}$ ), the horizontal light is seen to move to $\mathrm{d}$ (at speed $3+4=7$ $\mathrm{m} / \mathrm{sec}$ ), and the vertical to $\mathrm{b}\left(\right.$ at $\sqrt{3^{2}}+4^{2}=5 \mathrm{~m} / \mathrm{sec}$ ). In the next step the cabin moves from point a to A', the horizontal light moves from $\mathrm{d}^{\prime}$ to $\mathrm{A}^{\prime}$ (at speed 4-3=1 $\mathrm{m} / \mathrm{sec}$ ), and the vertical from b to $A^{\prime}$ (at $5 \mathrm{~m} / \mathrm{sec}$ ).

The vertical beam covered a total distance of 10 meters, the horizontal one $8 \mathrm{~m}$. They finally both return to the same corner of the cabin at the same time because their speeds differed, as determined by the person inside the cabin as well as an observer stationed outside. The expectation of a shift in interference fringes in Michelson's apparatus was therefore misplaced.

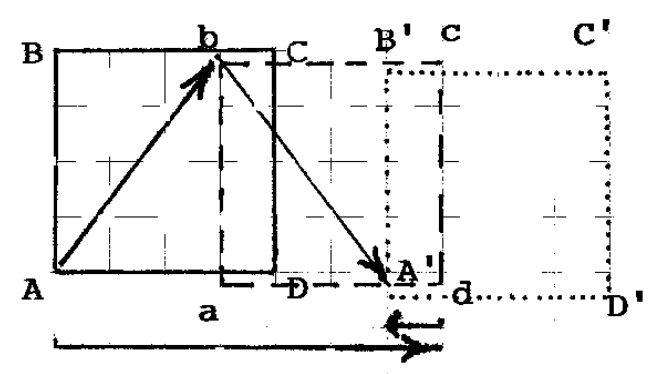

Fig. 2. Galilean kinematics.

\section{Lorentz' Interpretation}

Hendrik Antoon Lorentz (1853 - 1928), who was well familiar with Michelson's work, adopted the latter's definitions [5]: "If $\boldsymbol{l}$ is the distance of the points, $V$ the velocity of light, and $p$ that of earth, then ... making $a$ difference of... [emphasis added]" The velocity of light and the earth were again given in two different points of reference, and Michelson's results were taken at face value. This acceptance was probably eased by the extreme sensitivity of his apparatus, and by the work having originated in the laboratory of the famous Hermann
Helmholtz. "I have sought a long time to explain this experiment [the null result] without success, and eventually I found only one way to reconcile the result with Fresnel's theory. It consists of the assumption, that the line joining two points of a solid body doesn't conserve its length." Lorentz thus agreed with the hypothesis first made by George Francis FitzGerald [6]: The motion of light was independent of the motions of its source or its observer, hence the instrument's arm must have shrunk - the FitzGerald-Lorentz Contraction.

As a good friend and mentor of Einstein, Lorentz's interpretation of Michelson's experiments was readily accepted by him in his theories, as the "Principle of the constant velocity of light" $[7,8]$.

This "principle", evidently based on mistaken assumptions, was also directly contrary to old forgotten actual data, namely, those reported by Ole Roemer in 1676 [9]: Light from Jupiter's satellite Io traveled slower when he receded from it, and faster on approach, causing the periods of its revolutions to be longer on recession and shorter on approach [10]. ]:"For, as M. Roemer had examin'd the thing more nearly, he found, that...for example forty revolutions observed at the side $\mathrm{F}$ [on approach] might be sensibly shorter than forty others observed in any place of the Zodiak where Jupiter may be met with." $(\mathrm{V}=\mathrm{D} / \mathrm{T}$, for the same distance $\mathrm{D}$, when $\mathrm{T}$ increases $\mathrm{V}$ necessarily diminishes. Roemer's detailed data were not published till the twentieth century). Similar conclusions were reached by James Bradley [11]: The velocity of light from the star increased by that of the earth causing the angle of aberration $\left(\sqrt{ } v^{2}+c^{2}>c\right)$.

It is quite astounding that a small, subtle, yet fateful omission by Michelson was not corrected for over a century, caused perhaps by the awe and timidity Nobel Prizes instill in the hearts of man, an effect which may well be suitable for study by social psychologists. "A notion is a good slave but a bad master. Once it starts to constrain more than it stimulates it should be discarded. Loyalty to an idea is misplaced." [12] The idea of invariable speed of lights indeed posed such a constraint on the advancement of knowledge in optics [13].

Joseph Priestley's words about curious optical ideas of the eighteenth century apply equally well to the ether idea of the nineteenth and the speed of light of the twentieth: "Very lame and imperfect theories are sufficient to suggest useful experiments, which serve to correct these theories, and give birth to others more perfect. These, then, occasion further experiments, which brings us still nearer the truth; and in this method of approximation we must be content to proceed, and we ought to think ourselves happy, if, in this slow method, we make real progress." [14]

\section{References}

[1] Planck, M. The Universe in Light of Modern Physics. New York, NY, WW Norton, 60 (1941). 
[2] Michelson, A. Sur le movement relative de la Terre et de l'ether. Comtes Rendus 94, 520-23 (1882).

[3] Michelson, A. A. The relative motion of the Earth and the Luminiferous ether. Amer J Sc 22(3),xxii, 120-29 (1881)

[4] Michelson, A.A. Morley E W On the Relative Motion of the Earth and the Luminiferous Ether. Amer J Sc 34, 333- 345. (1887).

[5] Lorentz,H. http://en.wikisource.org/wiki/The Relative Motion_of the Earth_and_the_Aether. (1892). Accessed April 29, 2014.

[6] FitzGerald, G. F. The Ether and the Earth's Atmosphere. Science. 13. 390 (1889).

[7] Einstein, A. Über das Relativitätsprinzip und die aus Demselben gezogenen Folgerungen. Jahrbuch der Radioaktivität und Elektronik (4), 411-462 (1908).
[8] Einstein A. Die Relativitätstheorie. In Kultur der Gegenwart, Leipzig, B. G. Teubner (1), 703-713, (1915).

[9] Roemer, O. A Demonstration concerning the Motion of Light. Phil. Trans. Roy. Soc. 136, 233-36 (1677).

[10] Mach, E. The Principles of Physical Optics (1926), New York, NY, Dover Publication, 23, (c1953).

[11] Bradley, J. A new apparent Motion discovered in the Fixed Stars; its cause assigned; the Velocity and equable Motion of Light deduced. Phil Trans R. Soc. 35, 637-642 (1728).

[12] Murphy E. A. The Logic of Medicine, Baltimore, MD, Johns Hopkins Press, 24 (1976).

[13] Mark, H. H. Optokinetics, Bloomington, IN, Xlibris (2011).

[14] Priestley, J. The History and Present State of Discoveries relating to Vision, Light and Colours. London, J Johnson, 181 (1772). 